\title{
Solvent Effect on Ion-pair Extraction of 2-(2-Pyridylazo)-1- naphthol-4-sulfonate Anion with Solvated Hydroxonium Ion Using Alcohols and 1-Octanol/Octane Mixed Solvents
}

\author{
Tetsuyoshi NaIto, Yugo Tsuiki, and Hiromichi Yamada \\ Department of Applied Chemistry, Nagoya Institute of Technology, Gokiso, Showa, Nagoya 466-8555, Japan
}

\begin{abstract}
Extraction of 2-(2-pyridylazo)-1-naphthol-4-sulfonate anion with solvated hydroxonium ion was carried out using 14 kinds of alcohols and 1-octanol/octane mixed solvents as a solvent at $25^{\circ} \mathrm{C}$. Alcohols are 1-pentanol, 1-hexanol, 1heptanol, 2-heptanol, 3-heptanol, 4-heptanol, 1-octanol, 2-octanol, 3-octanol, 1-nonanol, 2-nonanol, 3-nonanol, 5-nonanol and 1-decanol. Among them, 1-octanol was found to be extremely high in extractability for 2-(2-pyridylazo)-1-naphthol4-sulfonate anion with hydroxonium cation. The extraction equilibrium for the systems using 1-octanol/octane mixed solvents was analyzed in detail in order to examine the extraction mechanism for these extraction systems. 2-(2Pyridylazo)-1-naphthol-4-sulfonate anion was found to be extracted with the hydroxonium ion solvated by three 1octanol molecules as an ion-pair. The extraction and partition constants of the ion-pair of 2-(2-pyridylazo)-1-naphthol-4sulfonate anion with solvated hydroxonium ion were estimated in the 1-octanol/octane mixed solvent systems.
\end{abstract}

(Received September 1, 2000; Accepted October 13, 2000)

In the ion association extraction a given ionic species forms an ion association complex with a counter ion in the aqueous phase and subsequently the complex partitions to the organic phase. Then, the ion association extraction is dependent on the formation constant of the ion association complex and its partition constant, which are influenced by the electrostatic and hydrophobic interactions.

Ferric ion is well known to be extracted as a solvated ion-pair, $\mathrm{H}^{+}, \mathrm{FeCl}_{4}{ }^{-}$from hydrogen chloride solution to diethyl ether or diisopropylether solutions. ${ }^{1}$ Tetrachloroferrate(III) anion is outlined to be extracted as $\mathrm{H}\left(\mathrm{H}_{2} \mathrm{O}\right) \mathrm{S}_{3}{ }^{+}, \mathrm{FeCl}_{4}{ }^{-}$(S: solvent) with isobutyl methyl ketone. ${ }^{2}$ In the previous work, the 1octanol/octane mixed solvent for the ion association extraction of copper(II) 2-(2-pyridylazo)-1-naphthol-4-sulfonate $\left(\mathrm{CuL}_{2}^{2-}\right)$ with tetrabutylammonium cation was found to be useful as a lower toxicity solvent than halogenated solvents from the point of view of preserving the natural environment. ${ }^{3}$ On that occasion, 2-(2-pyridylazo)-1-naphthol-4-sulfonate $\left(\mathrm{HL}^{-}\right)$was found to be appreciably extracted in the absence of tetrabutylammonium cation. In order to spread extensively the utility of the 1-octanol/octane mixed solvent, it is important to examine what kind of ion acts as a counter ion for the extraction of $\mathrm{HL}^{-}$anion. In future, the use of such low toxicity solvent as 1-octanol will spread, and hence it is indispensable to obtain the fundamental results for the low toxicity solvents in the various extraction systems.

In the present work, the effects of alcohol solvents on the extraction of 2-(2-pyridylazo)-1-naphthol-4-sulfonate anion with hydroxonium ion solvated by alcohol solvent molecules were investigated in detail in order to obtain the fundamental information on the utility of alcohols and 1-octanol/octane mixed solvents for the present ion association systems. The extraction equilibrium of 2-(2-pyridylazo)-1-naphthol-4sulfonate anion with a solvated hydroxonium cation was analyzed in detail for the 1-octanol/octane mixed solvent systems, since 1-octanol among the present alcohol solvents was revealed to be particularly useful for the present ion association extraction.

\section{Experimental}

\section{Reagents}

2-(2-Pyridylazo)-1-naphthol-4-sulfonic acid ( $\alpha$-PAN-4S: $\mathrm{H}_{2} \mathrm{~L}$ ): we used the same reagent as that used in the previous work. $^{3}$ 1-Pentanol, 1-hexanol, 1-heptanol and 1-octanol of reagent grades were obtained from Wako Pure Chemicals, Co., Ltd. 2-Heptanol, 3-heptanol, 3-octanol, 2-nonanol, 3-nonanol, 5-nonanol and 1-decanol of Extra Pure, and 4-heptanol and 2octanol of reagent grades were obtained from Tokyo Kasei Kogyo Co., Ltd., and 1-nonanol of reagent grade from Nacalai Tesque Inc. These alcohols were purified by washing successively with dilute sodium hydroxide, dilute perchloric acid solutions and distilled-deionized water. Octane of reagent grade obtained from Wako Pure Chemicals, Co., Ltd. was purified by the same methods as those previously described. ${ }^{3} \mathrm{~A}$ buffer solution at $\mathrm{pH}=5.6$ was prepared by adding the aqueous $\mathrm{NaOH}$ solution to the aqueous 2-morpholinoethanesulfonic acid monohydrate (MES obtained from Dojindo Laboratories, 99.0\%) solution. The other reagents were of reagent grade and were used without further purification. Aqueous solutions were prepared with distilled-deionized water.

\section{Procedure}

Partition was carried out using a 50-ml centrifuge tube placed in a thermostatic bath kept at $25^{\circ} \mathrm{C}$. A volume of $15 \mathrm{ml}$ each of aqueous and organic phases was shaken for about $1 \mathrm{~h}$, which was sufficient for complete equilibration. Extraction of $\alpha$-PAN$4 \mathrm{~S}$ monovalent anion $\left(\mathrm{HL}^{-}\right)$with hydroxonium cation into the various alcohol solvents was performed under the condition of 
Table 1 Distribution ratio of $\alpha$-PAN-4S and benzoic acid in the systems using various alcohol solvents

\begin{tabular}{rlcccc}
\hline & \multirow{2}{*}{ No. } & Solvent & $\delta_{\mathrm{o}} / \mathrm{J}^{1 / 2} \mathrm{~cm}^{-3 / 2}$ & $V_{\mathrm{o}} / \mathrm{cm}^{3}$ & \multicolumn{3}{c}{$D$-PAN-4S } & Benzoic acid \\
\hline 1 & & & & & \\
\hline & 1-pentanol & 22.7 & $108.8^{\mathrm{a}}$ & 0.879 & 85.1 \\
3 & 1-hexanol & 22.0 & $125.2^{\mathrm{a}}$ & 0.296 & 89.1 \\
3 & 1-heptanol & 21.5 & $141.9^{\mathrm{a}}$ & 0.132 & 87.1 \\
4 & 2-heptanol & 20.1 & $142.9^{\mathrm{a}}$ & 0.0335 & 97.7 \\
5 & 3-heptanol & 20.2 & $142.2^{\mathrm{a}}$ & 0.0337 & \\
6 & 4-heptanol & $19.2^{\mathrm{d}}$ & $142.0^{\mathrm{b}}$ & 26.5 & 91.2 \\
7 & 1-octanol & 21.1 & $158.4^{\mathrm{a}}$ & 635 & $69.2^{\mathrm{c}}$ \\
8 & 2-octanol & 19.1 & $159.4^{\mathrm{a}}$ & 9.66 & 87.1 \\
9 & 3-octanol & $18.8^{\mathrm{d}}$ & $159.5^{\mathrm{a}}$ & 0.0139 & 89.1 \\
10 & 1-nonanol & 20.7 & $175.3^{\mathrm{a}}$ & 0.0460 & 70.8 \\
11 & 2-nonanol & 18.5 & $176.2^{\mathrm{a}}$ & 0.0126 & 81.3 \\
12 & 3-nonanol & $19.6^{\mathrm{d}}$ & $174.9^{\mathrm{b}}$ & 0.0109 & \\
13 & 5-nonanol & $19.9^{\mathrm{d}}$ & $172.6^{\mathrm{b}}$ & 1.05 & 63.1 \\
14 & 1-decanol & 20.5 & $191.6^{\mathrm{a}}$ & 0.0363 & 63.1 \\
\hline
\end{tabular}

a. Ref. 10; b. Ref. 7; and c. Ref. 11. Molar volume was calculated by $V_{\mathrm{o}}=$ molecular weight/density cited from the respective references. d. These values were calculated according to the additivity of the solubility parameter of the constituent fragments.

keeping the $\mathrm{pH}$ at about 5.6 by MES-NaOH buffer solution. No influence of this buffer solution on the partition of $\mathrm{HL}^{-}$was observed. In the 1-octanol/octane mixed solvent systems, the value of $\mathrm{pH}$ in the aqueous phase was adjusted by a lithium hydroxide solution for the determination of the extraction and partition constants of the ion-pair, which consists of $\alpha$-PAN-4S monovalent anion with hydroxonium cation. Effects of lithium, sodium and potassium ions on the distribution ratio of $\alpha$-PAN$4 \mathrm{~S}\left(\mathrm{HL}^{-}\right)$were found to be very small up to $0.01 \mathrm{~mol} \mathrm{dm}^{-3}$, although the distribution ratio of $\alpha$-PAN-4S $\left(\mathrm{HL}^{-}\right)$was observed to be decreased in the presence of these cations more than 0.01 mol dm${ }^{-3}$. This lowering of the distribution ratio of $\alpha$-PAN-4S $\left(\mathrm{HL}^{-}\right)$in the coexistence of lithium ion was slightly less than in the presence of sodium or potassium cation. Then, lithium hydroxide was used for adjusting $\mathrm{pH}$. After centrifuging for 5 $\min$ at $3000 \mathrm{rpm}$, the concentration of $\alpha-\mathrm{PAN}-4 \mathrm{~S}\left(\mathrm{HL}^{-}\right)$in the aqueous phase was determined by measuring the absorbance at the wavelength of its absorption maximum $478 \mathrm{~nm}$, and that in the organic phase by deducing that in the aqueous phase from the initial concentration of $\alpha$-PAN-4S, $1.0 \times 10^{-4} \mathrm{~mol} \mathrm{dm}^{-3}$. Before measuring the absorbance, the aqueous phase was diluted by water as the need arose.

\section{Apparatus}

For mechanical shaking, centrifugation, measuring $\mathrm{pH}$ and absorption spectrum, the same pieces of apparatus as those in the previous work were used. ${ }^{3}$

\section{Results and Discussion}

Effects of alcohol solvents on the extraction of $\alpha-P A N-4 S$ anion $\left(H L^{-}\right)$with hydroxonium cation

The extraction of $\alpha$-PAN-4S anion with hydroxonium cation was carried out using various alcohols under the condition of keeping the $\mathrm{pH}$ at about 5.6. The distribution ratio of $\alpha$-PAN-4S obtained is shown in Table 1. As can be seen from the Table, the extractability was found to be extremely high in the

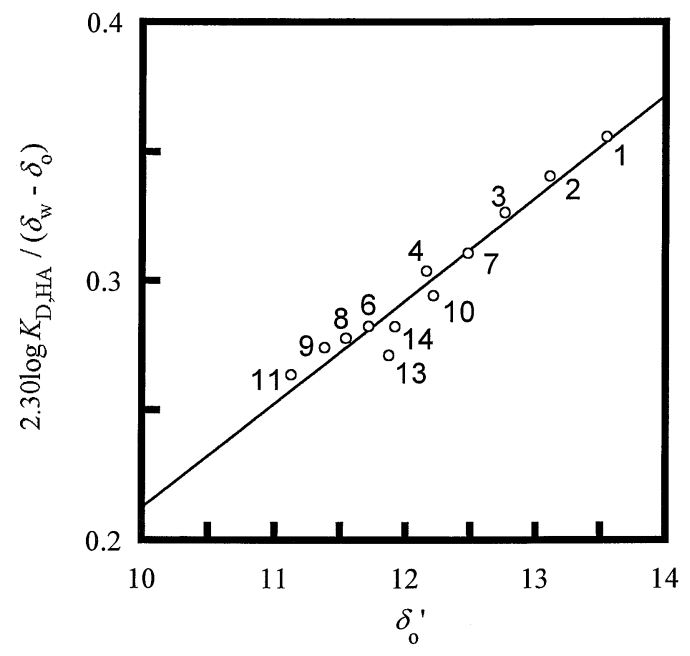

Fig. 1 Relationship of partition constant of benzoic acid with the solubility parameter of alcohols. Numbers denote respective alcohol solvents in Table 1.

extraction system using 1-octanol as a solvent. In the cases of using 4-heptanol and 2-octanol, a fairly high extractability was obtained. In the normal alcohol systems, the distribution ratio of $\alpha$-PAN-4S decreases with increasing the alkyl-chain length of alcohol, aside from 1-octanol. When 1-octanol is used, the distribution ratio of $\alpha$-PAN-4S is conspicuously large relative to the other alcohols. In the systems using heptanol, octanol and nonanol isomers, the distribution ratio of $\alpha$-PAN-4S was found to be strongly dependent on the position of the hydroxyl group. In heptanol and nonanol, each distribution ratio reveals the highest value in 4-heptanol and 5-nonanol, which are symmetrical, among the respective isomers. As noted above, the partition of $\alpha$-PAN-4S anion with hydroxonium cation was proven to be remarkably affected by the property of alcohols used as a solvent. For comparison the distribution ratio of

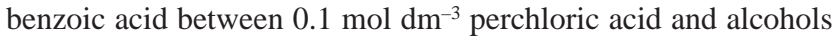
is also shown in Table 1 . In contrast to $\alpha$-PAN-4S, only small differences in the distribution ratio of benzoic acid were observed. Under the present conditions, the distribution ratio of benzoic acid can be regarded as the partition constant, that is, $D$ $=K_{\mathrm{D}, \mathrm{HA}}$.

According to the regular solution theory, the partition constant of an extracted species A, between the aqueous and organic phases is expressed by the following equation: ${ }^{4-6}$

$$
\frac{2.30 \log K_{\mathrm{D}, \mathrm{A}}}{\delta_{\mathrm{w}}-\delta_{\mathrm{o}}}=\frac{V_{\mathrm{A}}}{R T}\left(\delta_{\mathrm{w}}+\delta_{\mathrm{o}}{ }^{\prime}-2 \delta_{\mathrm{A}}\right),
$$

where

$$
\delta_{\mathrm{o}}^{\prime}=\delta_{\mathrm{o}}+\frac{R T}{\delta_{\mathrm{w}}-\delta_{\mathrm{o}}}\left(\frac{1}{V_{\mathrm{o}}}-\frac{1}{V_{\mathrm{w}}}\right),
$$

and $\delta_{\mathrm{w}}, \delta_{\mathrm{o}}, \delta_{\mathrm{A}}, V_{\mathrm{w}}, V_{\mathrm{o}}$ and $V_{\mathrm{A}}$ denote the solubility parameters and the molar volumes for water (the aqueous phase), the organic solvent and the extracted species A, respectively.

On the basis of Eq. (1), the plots of the left-hand side of Eq. (1) against $\delta_{0}^{\prime}$ for the partition of benzoic acid between each alcohol and $0.1 \mathrm{~mol} \mathrm{dm}^{-3}$ perchloric acid fit a straight line, as shown in Fig. 1. The value of $V_{\mathrm{A}}$ obtained from the slope is 98.6 $\mathrm{cm}^{3}$, which is close to the reported value of $96.5 \mathrm{~cm}^{3}{ }^{7}$ On the other hand, the plots of $2.30 \log D /\left(\delta_{\mathrm{w}}-\delta_{\mathrm{o}}\right)$ against $\delta_{\mathrm{o}}{ }^{\prime}$ for the 


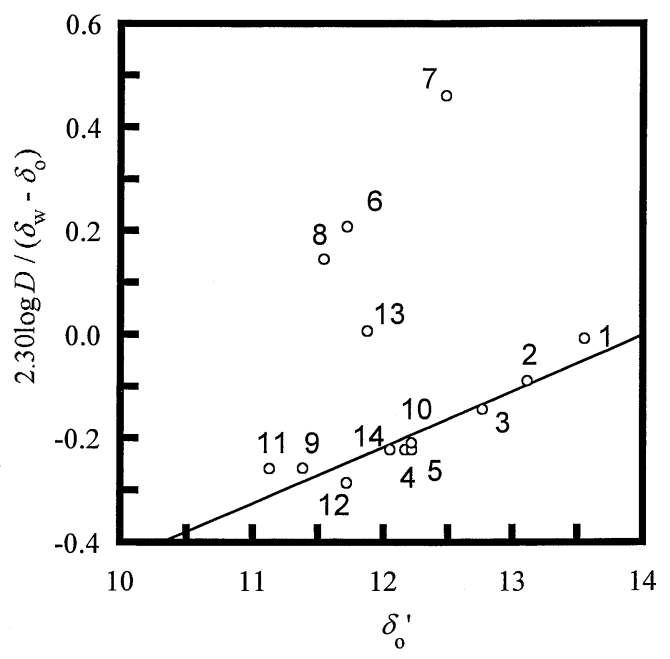

Fig. 2 Relationship of distribution ratio of $\alpha$-PAN-4S (HL-) with the solubility parameter of alcohols. Numbers are the same as in Fig. 1.

partition of $\alpha$-PAN-4S anion (HL-) with hydroxonium cation, which can be expected to be solvated by some alcohol molecules, are shown in Fig. 2. In these ion association extraction systems, if the partition constant of ion-pair $K_{\mathrm{D},(\mathrm{H}, \mathrm{HL},}$ can be approximated by the distribution ratio $D$ of $\alpha$-PAN-4S, the plots should follow a straight line. In contrast with benzoic acid, the plots for 4-hepatanol, 1-octanol, 2-octanol and 5nonanol deviate significantly upward from the straight line. These results suggest that in these alcohol systems, the solvation of a hydroxonium cation by alcohol molecules, the formation of ion-pair of $\alpha$-PAN-4S $\left(\mathrm{HL}^{-}\right)$anion with the solvated hydroxonium cation in the aqueous phase and the partition of the ion-pair are different in some way from those for the other alcohol systems. Although the plots other than 4-heptanol, 1octanol, 2-octanol and 5-nonanol fit a straight line, the molar volume of the ion-pair obtained from the slope of the straight line is much less than the value expected from $\alpha$-PAN-4S and 1-octanol. This suggests that the ion-pair-alcohol interaction is strongly operative to a similar extent in each alcohol solvent, except for the four kinds of alcohols listed above.

The analysis of the extraction equilibrium on $\alpha-P A N-4 S\left(H L^{-}\right)$ anion with hydroxonium cation solvated by 1-octanol molecules in the 1-octanol/octane mixed solvent systems

The partition of $\alpha$-PAN-4S anion $\left(\mathrm{HL}^{-}\right)$with hydroxonium cation, which is expected to be solvated by some 1-octanol molecules, was carried out using the 1-octanol/octane mixed solvents.

The partition equilibrium of this ion association system is expressed as:

$$
\begin{aligned}
& \mathrm{H}_{3} \mathrm{O}^{+}+n(\mathrm{ROH})_{\mathrm{o}}+\mathrm{HL}^{-} \rightleftharpoons\left(\mathrm{H}_{3} \mathrm{O}(\mathrm{ROH})_{n}{ }^{+}, \mathrm{HL}^{-}\right)_{\mathrm{o}} \\
& K_{\mathrm{ex}}=\frac{\left[\mathrm{H}_{3} \mathrm{O}(\mathrm{ROH})_{n}{ }^{+}, \mathrm{HL}^{-}\right]_{\mathrm{o}}}{\left[\mathrm{H}_{3} \mathrm{O}^{+}\right][\mathrm{ROH}]_{\mathrm{o}}{ }^{n}\left[\mathrm{HL}^{-}\right]},
\end{aligned}
$$

where the subscript o refers to the organic phase and $\mathrm{H}_{3} \mathrm{O}(\mathrm{ROH})_{n}{ }^{+}$denotes the hydroxonium cation solvated by $n$ numbers of 1-octanol molecules. This extraction equilibrium is dependent on the following equilibria.

Acid dissociation of $\alpha$-PAN-4S $\left(\mathrm{H}_{2} \mathrm{~L}\right)$ :

$$
\mathrm{H}_{2} \mathrm{~L}+\mathrm{H}_{2} \mathrm{O} \rightleftharpoons \mathrm{H}_{3} \mathrm{O}^{+}+\mathrm{HL}^{-}, K_{\mathrm{a} 1}=\left[\mathrm{H}_{3} \mathrm{O}^{+}\right]\left[\mathrm{HL}^{-}\right] /\left[\mathrm{H}_{2} \mathrm{~L}\right],
$$

$$
\mathrm{HL}^{-}+\mathrm{H}_{2} \mathrm{O} \rightleftharpoons \mathrm{H}_{3} \mathrm{O}^{+}+\mathrm{L}^{2-}, K_{\mathrm{a} 2}=\left[\mathrm{H}_{3} \mathrm{O}^{+}\right]\left[\mathrm{L}^{2-}\right] /\left[\mathrm{HL}^{-}\right] .
$$

Partition of 1-octanol between the aqueous phase and the mixed solvent:

$$
\mathrm{ROH} \rightleftharpoons(\mathrm{ROH})_{\mathrm{o}}, K_{\mathrm{D}, \mathrm{ROH}}=[\mathrm{ROH}]_{\mathrm{o}} /[\mathrm{ROH}]
$$

Solvation of $n$ numbers of 1-octanol molecules to hydroxonium cation in the aqueous phase:

$$
\begin{aligned}
& \mathrm{H}_{3} \mathrm{O}^{+}+n \mathrm{ROH} \rightleftharpoons \mathrm{H}_{3} \mathrm{O}(\mathrm{ROH})_{n}{ }^{+}, \\
& \beta_{\mathrm{sn}}=\left[\mathrm{H}_{3} \mathrm{O}(\mathrm{ROH})_{n}{ }^{+}\right] /\left[\mathrm{H}_{3} \mathrm{O}^{+}\right][\mathrm{ROH}]^{n} .
\end{aligned}
$$

Formation of ion-pairs of $\alpha$-PAN-4S anion ( $\left.\mathrm{HL}^{-}\right)$with solvated hydroxonium cations in the aqueous phase:

$$
\begin{aligned}
& \mathrm{H}_{3} \mathrm{O}(\mathrm{ROH})_{n}{ }^{+}+\mathrm{HL}^{-} \rightleftharpoons\left(\mathrm{H}_{3} \mathrm{O}(\mathrm{ROH})_{n}{ }^{+}, \mathrm{HL}^{-}\right), \\
& K_{\mathrm{f}}=\left[\mathrm{H}_{3} \mathrm{O}(\mathrm{ROH})_{n}{ }^{+}, \mathrm{HL}^{-}\right] /\left[\mathrm{H}_{3} \mathrm{O}(\mathrm{ROH})_{n}{ }^{+}\right]\left[\mathrm{HL}^{-}\right] .
\end{aligned}
$$

Partition of the ion-pairs between the aqueous and organic phases:

$$
\begin{aligned}
& \left(\mathrm{H}_{3} \mathrm{O}(\mathrm{ROH})_{n}{ }^{+}, \mathrm{HL}^{-}\right) \rightleftharpoons\left(\mathrm{H}_{3} \mathrm{O}(\mathrm{ROH})_{n}{ }^{+}, \mathrm{HL}^{-}\right)_{\mathrm{o}} \\
& K_{\mathrm{D},(\mathrm{H}, \mathrm{HL})}=\left[\mathrm{H}_{3} \mathrm{O}(\mathrm{ROH})_{n}{ }^{+}, \mathrm{HL}^{-}\right]_{\mathrm{o}} /\left[\mathrm{H}_{3} \mathrm{O}(\mathrm{ROH})_{n}{ }^{+}, \mathrm{HL}^{-}\right] .
\end{aligned}
$$

Then, the extraction constant can be rewritten from Eqs. (3), (6) - (9):

$$
K_{\mathrm{ex}}=K_{\mathrm{D},(\mathrm{H}, \mathrm{HL})} K_{\mathrm{f}} \beta_{\mathrm{sn}} K_{\mathrm{D}, \mathrm{ROH}^{-n}} .
$$

The distribution ratio of $\alpha$-PAN-4S can be expressed in the $\mathrm{pH}$ region, in which $\mathrm{HL}^{-}$species prevails in the aqueous phase, by the following expression:

$$
\begin{array}{r}
D_{\mathrm{HL}}=\frac{\left[\mathrm{H}_{3} \mathrm{O}(\mathrm{ROH})_{n}{ }^{+}, \mathrm{HL}^{-}\right]_{\mathrm{o}}}{\left[\mathrm{HL}^{-}\right]+\left[\mathrm{H}_{3} \mathrm{O}(\mathrm{ROH})_{n}{ }^{+}, \mathrm{HL}^{-}\right]} \\
=\frac{K_{\mathrm{ex}}[\mathrm{ROH}]_{\circ}{ }^{n}\left[\mathrm{H}_{3} \mathrm{O}^{+}\right]}{1+K_{\mathrm{f}} \beta_{\mathrm{sn}}[\mathrm{ROH}]^{n}\left[\mathrm{H}_{3} \mathrm{O}^{+}\right]}
\end{array}
$$

The following equation is obtained by taking logarithms of Eq. (11):

$$
\begin{aligned}
\log D_{\mathrm{HL}}= & n \log [\mathrm{ROH}]_{\mathrm{o}}+\log \left[\mathrm{H}_{3} \mathrm{O}^{+}\right]+\log K_{\mathrm{ex}} \\
& -\log \left(1+K_{\mathrm{f}} \beta_{\text {sn }}[\mathrm{ROH}]^{n}\left[\mathrm{H}_{3} \mathrm{O}^{+}\right]\right),
\end{aligned}
$$

where $[\mathrm{ROH}]$ denotes the concentration of 1-octanol in the aqueous phase, and is equal to the saturated 1-octanol concentration in the aqueous phase at equilibrium. Then, the plots of $\log D_{\mathrm{HL}}$ against $\log [\mathrm{ROH}]_{\text {。 }}$ under the conditions at constant $\left[\mathrm{H}_{3} \mathrm{O}^{+}\right]$should follow a straight line, if $\log K_{\text {ex }}$ can be approximated to be constant. As shown in Fig. 3, the plots fit well a straight line with a slope of 3.0. This suggests that the hydroxonium cation is solvated by three 1-octanol molecules.

In addition, another equation can be derived from Eqs. (6), (10) and (11):

$$
\frac{\left[\mathrm{H}_{3} \mathrm{O}^{+}\right]}{D_{\mathrm{HL}}}=\frac{1}{K_{\mathrm{D},(\mathrm{H}, \mathrm{HL})}}\left[\mathrm{H}_{3} \mathrm{O}^{+}\right]+\frac{1}{K_{\mathrm{ex}}[\mathrm{ROH}]_{\mathrm{o}}{ }^{3}}
$$

where $n$ in Eq. (11) is found to be 3 from the slope of the straight line as noted above. According to Eq. (13), the partition 


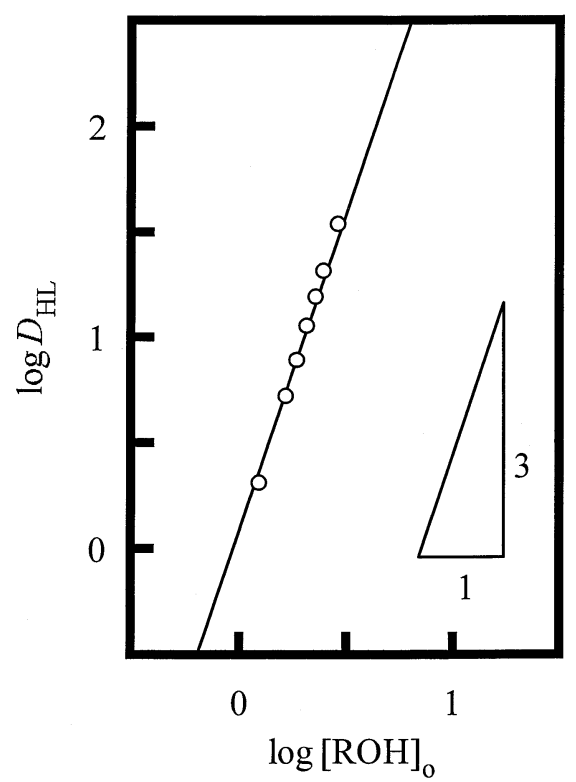

Fig. 3 Determination of the number of 1-octanol molecules solvated on hydroxonium ion. Solid line is a straight line with a slope of 3.0.

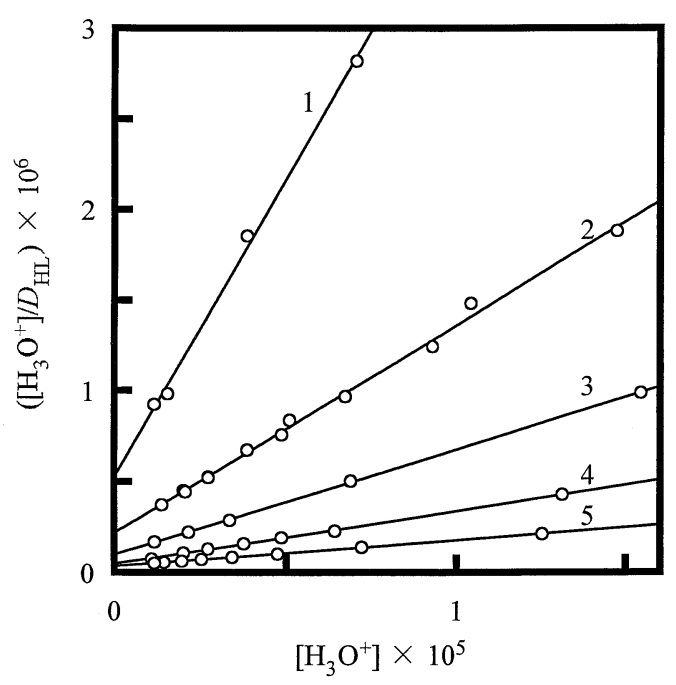

Fig. 4 Estimation of the partition and extraction constants of the ion-pair, $\mathrm{H}_{3} \mathrm{O}(\mathrm{ROH})_{3}{ }_{3}^{+}, \mathrm{HL}^{-} . C_{\alpha-\mathrm{PAN}-4 \mathrm{~S}}=1.0 \times 10^{-4} \mathrm{~mol} \mathrm{dm}{ }^{-3}$. Solid lines are srtraight ones drawn by the least-squares method. Numbers denote the respective mixed solvents in Table 2.

and the extraction constants of the ion-pair, $\left(\mathrm{H}_{3} \mathrm{O}(\mathrm{ROH})_{3}{ }^{+}, \mathrm{HL}^{-}\right)$ are obtained from the slope and intercept of the straight line by the plots of the left-hand side of Eq. (13) against $\left[\mathrm{H}_{3} \mathrm{O}^{+}\right]$at constant $[\mathrm{ROH}]_{\mathrm{o}}$. As can be seen from Fig. 4, the plots follow well each straight line for the respective mixed solvent systems. The values of partition and extraction constants obtained are summarized in Table 2. The extraction constant of $\left(\mathrm{H}_{3} \mathrm{O}(\mathrm{ROH})_{3}{ }^{+}, \mathrm{HL}^{-}\right)$under the present extraction conditions was found to be approximately constant irrespective of the concentration of 1-octanol in the mixed solvents, as expected above. The partition constant of the ion-pair is increased with increasing the concentration of 1-octanol in the mixed solvents. The ion-pair appears to have a strong affinity for 1-octanol solvent.
Table 2 The extraction and partition constants of the ion-pair, $\left(\mathrm{H}_{3} \mathrm{O}(\mathrm{ROH})_{3}{ }^{+}, \mathrm{HL}^{-}\right)$

\begin{tabular}{cccc}
\hline No. & $\begin{array}{c}{[\mathrm{ROH}]_{\mathrm{o}} \text { in the mixed solvents/ }} \\
\mathrm{mol} \mathrm{dm}^{-3}\end{array}$ & $\log K_{\mathrm{ex}}$ & $\log K_{\mathrm{D}, \mathrm{H}, \mathrm{HL})}$ \\
\hline 1 & 1.5 & 5.77 & 0.48 \\
2 & 2.0 & 5.78 & 0.94 \\
3 & 2.5 & 5.85 & 1.24 \\
4 & 3.0 & 5.97 & 1.54 \\
5 & 3.5 & 5.94 & 1.85 \\
\hline
\end{tabular}

Table 3 The partition constant of 1-octanol between water and 1 -octanol/octane mixed solvent, and the product of the solvation and ion-pair formation constants $\left(K_{\mathrm{f}} \cdot \beta_{\mathrm{S} 3}\right)$

\begin{tabular}{cccc}
\hline No. & $\begin{array}{c}{[\mathrm{ROH}]_{\mathrm{o}} \text { in the mixed solvents/ }} \\
\mathrm{mol} \mathrm{dm}^{-3}\end{array}$ & $\log K_{\mathrm{D}, \mathrm{ROH}}$ & $\log K_{\mathrm{f}}+\log \beta_{\mathrm{S} 3}$ \\
\hline 1 & 1.5 & 2.60 & 13.15 \\
2 & 2.0 & 2.72 & 13.00 \\
3 & 2.5 & 2.82 & 13.04 \\
4 & 3.0 & 2.90 & 13.13 \\
5 & 3.5 & 2.96 & 12.97 \\
\hline
\end{tabular}

Taking logarithms of Eq. (10) leads to the following equation:

$$
\log K_{\mathrm{ex}}-\log K_{\mathrm{D},(\mathrm{H}, \mathrm{HL})}+3 \log K_{\mathrm{D}, \mathrm{ROH}}=\log K_{\mathrm{f}}+\log \beta_{\mathrm{S} 3}
$$

where three kinds of constants on the left-hand side of the equation are responsible for the two phases, but the two kinds of constants on the right-hand side refer only to the aqueous phase. As described above, $[\mathrm{ROH}]$ can be regarded as the saturated 1octanol concentration in the aqueous phase $\left([\mathrm{ROH}]_{\mathrm{sat}}=0.0038\right.$ mol dm $\left.{ }^{-3}\right),{ }^{8}$ because the aqueous phase was saturated with 1 octanol at extraction equilibrium. Then, $[\mathrm{ROH}]_{\mathrm{o}}=C_{\mathrm{ROH}}-$ 0.0038 , that is, $K_{\mathrm{D}, \mathrm{ROH}}=\left(C_{\mathrm{ROH}}-0.0038\right) / 0.0038$, where $C_{\mathrm{ROH}}$ denotes the initial concentration of 1-octanol in the mixed solvents. The calculated partition constants are summarized together with the values of $\left(\log K_{\mathrm{f}}+\log \beta_{\mathrm{S} 3}\right)$, which were obtained by Eq. (14), in Table 3. The sum of these constants is expected to be constant irrespective of the composition of 1 octanol/octane mixed solvent, since both reactions occur in the aqueous phase. As expected, the sum of $\log K_{\mathrm{f}}$ and $\log \beta_{\mathrm{S} 3}$ can be approximately constant. From these facts, the validity of the present results is also supported.

Structure of the hydroxonium cation solvated by three numbers of 1-octanol molecules

A proton is well known to exist as a hydrated proton, namely hydroxonium ion $\mathrm{H}_{3} \mathrm{O}^{+}$in water and the hydration number of a proton has been estimated to be about four. Hydroxonium ion $\mathrm{H}_{3} \mathrm{O}^{+}$has planar triangular structure and then, three water molecules bond to three hydogen atoms at the vertices of a triangle. ${ }^{9}$ The solvation of hydroxonium cation by three 1 octanol molecules can be regarded as the substitution reaction of three water molecules by three 1-octanol molecules. Then, the structure of hydroxonium cation solvated by three 1-octanol molecules can be expected to be similar to that of a hydrated proton, $\mathrm{H}_{9} \mathrm{O}_{4}^{+}$.

Taking into account the solvation number of 1-octanol molecule to the hydroxonium ion and the structure of solvated hydroxonium ion, the extractability of $\alpha$-PAN-4S monovalent 
anion $\left(\mathrm{HL}^{-}\right)$in the present extraction systems using various alcohols as a solvent is expected to be primarily dependent on the solvation reaction of each alcohol molecule with the hydroxonium ion. In other words, the steric and inductive effects of alkyl substituent in the respective alcohol molecules on the solvation reaction and the solubility of each alcohol in the aqueous phase are predicted to govern the extractability of the present extraction systems.

\section{References}

1. G. H. Morrison and H. Freiser, "Solvent Extraction in Analytical Chemistry", 1957, John Wiley \& Sons, New York, 62

2. J. A. Dean, "Analytical Chemistry Handbook", 1995 McGraw-Hill, New York, 2.22.

3. H. Yamada, K. Teranishi, H. Niwa, Y. Shigematsu, T.
Uchida, and H. Wada, Anal. Sci., 1997, 13, 545.

4. T. Wakahayashi, S. Oki, T. Omori, and N. Suzuki, J. Inorg. Nucl. Chem., 1964, 26, 2255.

5. I. Kojima, M. Yoshida, and M. Tanaka, J. Inorg. Nucl. Chem., 1970, 32, 987

6. H. Yamada and M. Tanaka, J. Inorg. Nucl. Chem., 1976, 38,1501 .

7. D. R. Lide, "CRC Handbook of Chemistry and Physics", 74th ed., 1993 - 1994, 1993, CRC Press, Boca Raton.

8. K. Kinoshita, H. Ishikawa, and K. Shinoda, Bull. Chem. Soc. Jpn., 1958, 31, 1081.

9. H. Ohtaki, "Yoeki no Kagaku (Solution Chemistry, in Japanese)", 1987, Dainihontosho, Tokyo, 129.

10. A. F. M. Barton, "CRC Handbook of Solubility Parameters and Other Cohesion Parameters", 2nd ed., 1991, CRC Press, Boca Raton

11. H. Yamada, K. Yajima, H. Wada, and G. Nakagawa, Talanta, 1995, 42, 789. 